\title{
Research on the Secondary Forgeability of High Volume Fraction Whisker Reinforced Aluminum Matrix Composites of Original Squeeze Casting
}

\author{
Shucong $X u^{1,2}$, Lin Yuan ${ }^{1,2, *}$, Lei Wang ${ }^{1,2}$, Jinyu Li ${ }^{1,2}$, Fuchang $X u^{1,2}$, Zhenzhu Zheng ${ }^{1,2}$, Debin Shan ${ }^{1,2}$ \\ and Bin Guo ${ }^{1,2}$ \\ 1 National Key Laboratory for Precision Hot Processing of Metals, Harbin 150001, China; \\ xushucong1995@163.com (S.X.); allengineer@163.com (L.W.); LJY02150301@163.com (J.L.); \\ xfch@hit.edu.cn (F.X.); zzzheng@hit.edu.cn (Z.Z.); shandebin@hit.edu.cn (D.S.); guobin@hit.edu.cn (B.G.) \\ 2 School of Materials Science and Engineering, Harbin Institute of Technology, No. 92 Xi Dazhi Street, \\ Harbin 150001, China \\ * Correspondence: yuanlin@hit.edu.cn; Tel.: +86-451-86416221
}

Citation: Xu, S.; Yuan, L.; Wang, L.; Li, J.; Xu, F.; Zheng, Z.; Shan, D.; Guo, B. Research on the Secondary Forgeability of High Volume Fraction Whisker Reinforced Aluminum Matrix Composites of Original Squeeze Casting. Materials 2021, 14 7261. https://doi.org/10.3390/ ma14237261

Academic Editor: Theodore E. Matikas

Received: 15 October 2021

Accepted: 24 November 2021

Published: 27 November 2021

Publisher's Note: MDPI stays neutral with regard to jurisdictional claims in published maps and institutional affiliations.

Copyright: (c) 2021 by the authors. Licensee MDPI, Basel, Switzerland. This article is an open access article distributed under the terms and conditions of the Creative Commons Attribution (CC BY) license (https:/ / creativecommons.org/licenses/by/ $4.0 /)$.

\begin{abstract}
The poor formability of high volume fraction whisker reinforced aluminum matrix composites of original squeeze casting is an important factor restricting its further development and application. Currently, there are no reports on the secondary forgeability of aluminum matrix composites of original squeeze casting, although some papers on its first forgeability are published. The secondary forgeability is very important for most metals. This study aims to investigate the secondary forgeability of aluminum matrix composites. In this study, the secondary upsetting experiments of $20 \mathrm{vol} \% \mathrm{SiCw}+\mathrm{Al}_{18} \mathrm{~B}_{4} \mathrm{O}_{33} \mathrm{w} / 2024 \mathrm{Al}$ composites, treated by the original squeeze casting and extrusion, were carried out. The first upsetting deformation is close to the forming limit, the secondary upsetting deformation under the same deformation conditions was carried out to investigate the secondary forgeability. The experimental results show that, unlike aluminum alloys, the $20 \mathrm{vol} \% \mathrm{SiCw}+\mathrm{Al}_{18} \mathrm{~B}_{4} \mathrm{O}_{33} \mathrm{w} / 2024 \mathrm{Al}$ composites at the original squeeze casting and extrusion states have no secondary forgeability due to the whisker rotating and breaking during the secondary upsetting. The high volume fraction whisker reinforced aluminum matrix composites of original squeeze casting cannot be formed by the multiple-forging method since the cavities and cracks caused by whisker fracture continue to expand during secondary processing, which leads to further extension of macroscopic cracks.
\end{abstract}

Keywords: whiskers; aluminum matrix composites; forging; secondary forgeability

\section{Introduction}

Metal matrix composites (MMCs), especially those based on light metals such as aluminum alloys, have become an indispensable lightweight structural material in hightech areas such as defense aerospace and military equipment due to its advantages of light mass, high strength, well thermal stability, wear resistance and low thermal expansion coefficient [1-12]. However, MMCs have low elongation, poor plastic forming ability and low material utilization, making it difficult to form complex parts, which is the most important reason to limit their application [13-19].

Aluminum matrix composites have poor forgeability and a narrow forging temperature range. Deformation of composites is affected by matrix, reinforcement and strain rate [20]. During the plastic deformation process, the reinforcement added to the aluminum matrix composite will fracture easily due to its brittleness and hardness. Microcracks will be induced in the matrix, which reduces the thermoplastic deformation ability of the aluminum matrix composite [21].

To reduce the costs in the industrial production, the original squeeze casting is often used to prepare composite materials. Aluminum matrix composite materials prepared by 
original squeeze casting usually have casting defects such as pinholes, pores, reinforcement aggregates and low interfacial bonding. The stress concentration will be caused by these defects during plastic deformation which will lead to cracking and poor processing ability [22]. Aluminum matrix composites of high volume fraction whisker reinforced often have an elongation of less than $5 \%$ at room temperature. Even at high temperatures, the elongation of composites is difficult to increase by common forming processes. The poor formability of aluminum matrix composites has become an important reason for delaying further application of aluminum matrix composites of original squeeze casting [23]. Fu et al. proposed that the same multi-step forming as ordinary metals could be tried to increase the forgeability of high volume fraction whisker reinforced aluminum matrix composites [24]. The research on the secondary forgeability has practical significance for the development of new processing technology of the aluminum matrix composites.

Some relevant research on the first forgeability have been done in recent years. $\mathrm{SiCp} / 6066$ aluminum matrix composites with different volume fractions were prepared by Hu et al. [25] using canned hot extrusion, the relationship between SiCp volume fraction and tensile strength as well as yield strength was studied. The results show that as the volume fraction of the reinforcement increases, the strength of the composite material is improved. When the volume fraction of $\mathrm{SiCp}$ is greater than $12 \%$, the strength of the material decreases. A hot extrusion deformation at the extrusion ratio of 25:1 of SiCp/Al with a particle volume content of $25 \%$ were performed by Qu et al. [26] who found that hot extrusion deformation can greatly improve the strength, modulus and plasticity of composites. Compared with the base alloy, Zhang et al. [27] found that the elongation of hybrid reinforced composites such as $\mathrm{SiCw} \cdot \mathrm{SiCp} / 2024 \mathrm{Al}$ decreases, the hot extrusion is beneficial to improve the elongation of hybrid composites. Xu et al. [28] found that the partial melting and occurrence of dynamic recrystallization at high temperature and high strain rate could effectively avoid the formation of cracks and improve the hot workability of $20 \mathrm{vol} \% \mathrm{SiCw} / 6061$ aluminum matrix composites. Yuan et al. [29] prepared the aluminum matrix composites reinforced by aluminum borate whisker with or without $\mathrm{Bi}_{2} \mathrm{O}_{3}$ coating by squeeze casting. It was found that $\mathrm{ABOw} / \mathrm{Bi}_{2} \mathrm{O}_{3} / \mathrm{Al}$ composites have high plastic forming properties. During the preparation process, $\mathrm{Bi}_{2} \mathrm{O}_{3}$ coating react with aluminum matrix in the composite, which forms Bi phase at the interface between whisker and matrix. The fracture of the whisker is obviously reduced and the forming property of the composite is improved. Leng et al. [30] added graphite with different volume fractions and particle sizes, $\mathrm{SiC} / \mathrm{Gr} / \mathrm{Al}$ composites were prepared by squeeze casting, the results show that the elastic modulus of the composites tends to decrease with the increasing of volume fraction and particle size of graphite. Both the tensile strength and the elastic modulus depended on the volume fraction and the particle sizes of graphite. However, only single pass forgeability study of aluminum-based composites has been carried out, whether there is no relevant research on the secondary forgeability of the aluminum matrix composites reinforced with high volume fraction whiskers. The secondary forgeability is very important for most of metals. Therefore, the research on secondary forgeability of aluminum matrix composites has important practical significance.

This paper studies the forging deformation behavior of $20 \mathrm{vol} \% \mathrm{SiCW}+\mathrm{Al}_{18} \mathrm{~B}_{4} \mathrm{O}_{33} \mathrm{~W} /$ $2024 \mathrm{Al}$ composites, explores the secondary forgeability of whisker-reinforced $20 \mathrm{vol} \% \mathrm{SiCw}$ $+\mathrm{Al}_{18} \mathrm{~B}_{4} \mathrm{O}_{33} \mathrm{~W} / 2024 \mathrm{Al}$ composites of original squeeze casting, and provides a reference for the design of the thermoplastic forming process for high volume fraction whiskerreinforced aluminum matrix composites of original squeeze casting.

\section{Materials and Methods}

\subsection{Materials}

The material used in the experiment is $20 \mathrm{vol} \% \mathrm{SiCw}+\mathrm{Al}_{18} \mathrm{~B}_{4} \mathrm{O}_{33} \mathrm{w} / 2024 \mathrm{Al}$ prepared by original squeeze casting. The chemical composition of $\mathrm{SiCw}+\mathrm{Al}_{18} \mathrm{~B}_{4} \mathrm{O}_{33} \mathrm{~W} / 2024 \mathrm{Al}$ is shown in Table 1 . The total volume fraction of the whisker reinforcement is $20 \%$, and the ratio of $\mathrm{SiCw}$ to $\mathrm{Al}_{18} \mathrm{~B}_{4} \mathrm{O}_{33} \mathrm{~W}$ is 1:4. The $\mathrm{SiC}$ whisker is $\beta-\mathrm{SiC}$ with a diameter of $0.1-1.0 \mu \mathrm{m}$ 
and a length of $10-50 \mu \mathrm{m}$, the $\mathrm{Al}_{18} \mathrm{~B}_{4} \mathrm{O}_{33} \mathrm{~W}$ whisker has a diameter of $0.5-1.0 \mu \mathrm{m}$ and a length of $10-30 \mu \mathrm{m}$, the matrix is the 2024 aluminum alloy. The material was prepared by secondary pressure processing, including low-pressure infiltration and high-pressure holding and cooling. The preformed block and the mold were preheated to $500-520^{\circ} \mathrm{C}$ and the heat was preserved, while the aluminum alloy was heated to $700-800{ }^{\circ} \mathrm{C}$ to melt and maintain the temperature. Then, the aluminum alloy was poured into the preheated mold, and the indenter pressurized the aluminum alloy in the molten state at a speed of $2 \mathrm{~mm} / \mathrm{s}$, and holding the pressure at 50-60 MPa for $10 \mathrm{~min}$.

Table 1. Chemical composition of 2024 aluminum alloy (mass fraction wt.\%).

\begin{tabular}{ccccccccc}
\hline $\mathbf{S i}$ & $\mathbf{F e}$ & $\mathbf{C u}$ & $\mathbf{M n}$ & $\mathbf{M g}$ & $\mathbf{Z n}$ & $\mathbf{T i}$ & $\mathbf{C r}$ & $\mathbf{A l}$ \\
\hline 0.5 & 0.5 & $3.5-4.9$ & $0.3-0.9$ & $1.2-1.8$ & 0.25 & 0.15 & 0.10 & other \\
\hline
\end{tabular}

\subsection{Methods}

\subsubsection{Extrusion Experiment}

The extrusion test was performed, and the research on secondary forgeability of extruded aluminum matrix composites can be carried out. The extrusion experiment of $\mathrm{SiCw}+\mathrm{Al}_{18} \mathrm{~B}_{4} \mathrm{O}_{33} \mathrm{~W} / 2024 \mathrm{Al}$ composite material was carried out using a $1600 \mathrm{t}$ hydraulic press, the hydraulic press and extrusion die are shown in Figure 1. The diameter of the upper part of the extrusion die cavity is $\varphi 74 \mathrm{~mm}$, the depth is $100 \mathrm{~mm}$, the central cone angle is $120^{\circ}$, the arc boundary transition is $10 \mathrm{~mm}$, the extrusion diameter is $25 \mathrm{~mm}$ and the extrusion ratio is 9:1. The size of the original billet is $\varphi 72 \mathrm{~mm} \times 60 \mathrm{~mm}$. Heating the billet and the extrusion die with a heating furnace, the billet was taken out when it was heated about $10 \mathrm{~min}$, the graphite lubricant was brushed on the surface. Then, it was placed in the heating furnace, heated to the specified temperature and held for $2 \mathrm{~h}$. After the extruding, the billet was cooled in air.
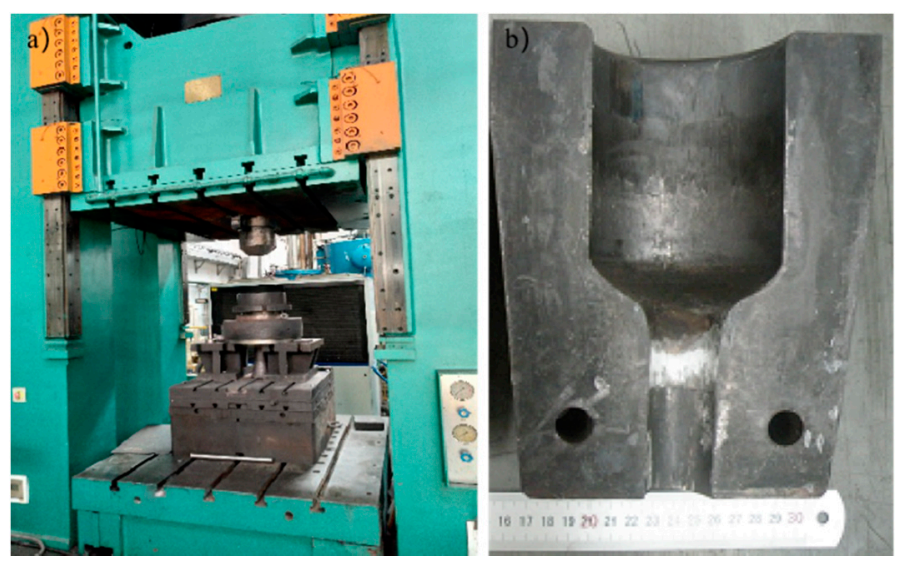

Figure 1. Hydraulic press and die used in extrusion experiments: (a) The 1600 thydraulic press; (b) The extrusion die.

\subsubsection{Upsetting Experiment}

The upsetting tests were performed on composites of the original squeeze casting and extrusion. Two sizes of samples were used in the upsetting tests. The distribution of the reinforcing phase of the original squeeze casting is uneven, so large samples with the size of $60 \mathrm{~mm} \times 60 \mathrm{~mm} \times 60 \mathrm{~mm}$ were used for the upsetting test. Given the extrusion composite material has been deformed, the distribution of the reinforcing phase is uniform, and the forgeability is improved, there is no need to use large samples, so small samples with the size of $14 \mathrm{~mm} \times 14 \mathrm{~mm} \times 14 \mathrm{~mm}$ were used for the upsetting test.

The upsetting test was performed on samples with a size of $14 \mathrm{~mm} \times 14 \mathrm{~mm} \times 14 \mathrm{~mm}$ under the AG-X Plus electronic universal testing machine. The samples were placed in the 
test machine and heat preserved for $30 \mathrm{~min}$. After upsetting in the axial direction, quenching the compressed composites in cold water to retain the microstructure. The upsetting test was performed on samples with a size of $60 \mathrm{~mm} \times 60 \mathrm{~mm} \times 60 \mathrm{~mm}$ under a $5000 \mathrm{t}$ press. The samples were heated to the specified temperature and heat preserved for $1 \mathrm{~h}$. Upsetting the samples took place in the direction of pressure during the squeeze casting, then the compressed composites were quenched in cold water to retain the microstructure.

\section{Results}

\subsection{The Sheathed Extrusion of the Aluminum Matrix Composites of Original Squeeze} Casting Samples

The sheath was a pure aluminum ring with the outer diameter of $\varphi 72 \mathrm{~mm}$, the inner diameter of $\varphi 60 \mathrm{~mm}$ and the height of $60 \mathrm{~mm}$. The size of the billets of aluminum-based composite material is $\varphi 60 \mathrm{~mm} \times 60 \mathrm{~mm}$. The billet and extruded bars are shown in Figure 2 .

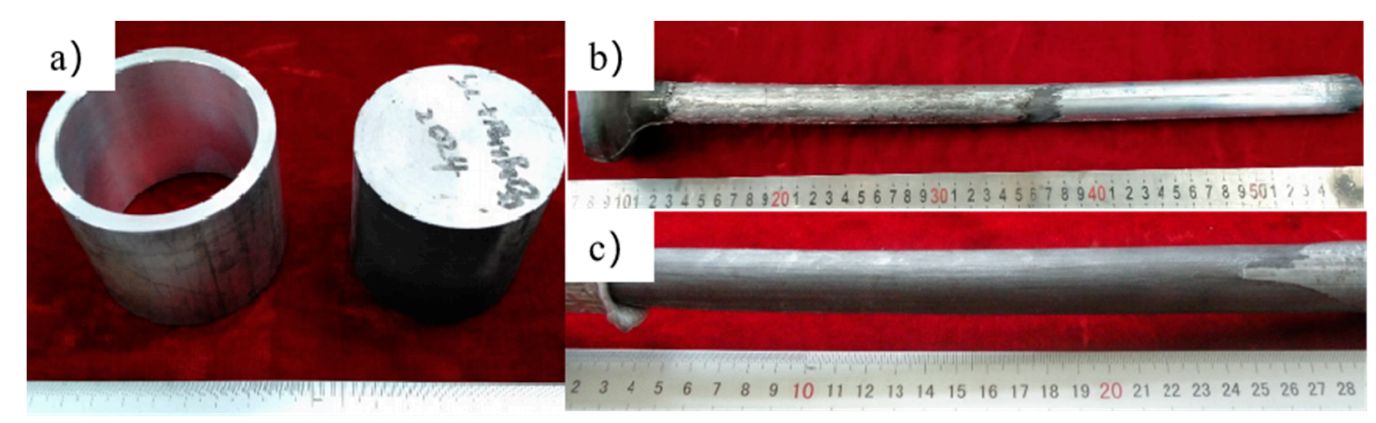

Figure 2. The billet and extruded bars of sheathed extrusion: (a) The billet of aluminum matrix composite with the size of $\varphi 60 \mathrm{~mm} \times 60 \mathrm{~mm}$ and the pure aluminum sheath; (b) The surface of $\mathrm{SiCW}+\mathrm{Al}_{18} \mathrm{~B}_{4} \mathrm{O}_{33} \mathrm{~W} / 2024 \mathrm{Al}$ composite extruded bars by sheathed extrusion; (c) The surface of $\mathrm{SiCw}+\mathrm{Al}_{18} \mathrm{~B}_{4} \mathrm{O}_{33} \mathrm{~W} / 2024 \mathrm{Al}$ composite extruded bars by sheathed extrusion after removing the sheath.

The experiment results show that although there are few transverse cracks on the sheath, the surface of $\mathrm{SiCw}+\mathrm{Al}_{18} \mathrm{~B}_{4} \mathrm{O}_{33} \mathrm{~W} / 2024 \mathrm{Al}$ composite has no macro cracks after removing the sheath, indicating that the forming quality of the composite is excellent. This is because that the pure aluminum sheath avoids the direct contact of the composite and the extrusion die, which reduces the surface friction. In addition, the sheath also has a thermal insulation effect on the aluminum-based composite material, which makes the internal aluminum matrix composite cool down more slowly, improving the forming ability of the aluminum matrix composites.

\subsection{The Secondary Forgeability of the Aluminum Matrix Composites of Original Squeeze Casting Samples}

3.2.1. The First Forging Limit of the Original Squeeze Casting Samples

The sample morphology of the aluminum matrix composite after the upsetting test is shown in Figure 3. When the axial compression deformation amount was $32.43 \%$, the sample height after compression was $40.30 \mathrm{~mm}$. There were no macroscopic cracks on the surface of the sample. When the axial compression deformation amount was $34.28 \%$, the sample height after compression was $39.43 \mathrm{~mm}$. Deep macro cracks appeared on the surface of the sample, and the direction of the cracks were parallel to the compression direction. The first forging limit of the aluminum matrix composite of original squeeze casting is $32.43 \%$.

\subsubsection{The Secondary Upsetting Experiment of the Original Squeeze Casting Samples}

The upsetting experiments of the $\mathrm{SiCw}+\mathrm{Al}_{18} \mathrm{~B}_{4} \mathrm{O}_{33} \mathrm{w} / 2024 \mathrm{Al}$ composite samples of the original squeeze casting were carried out, as shown in Table 2. 

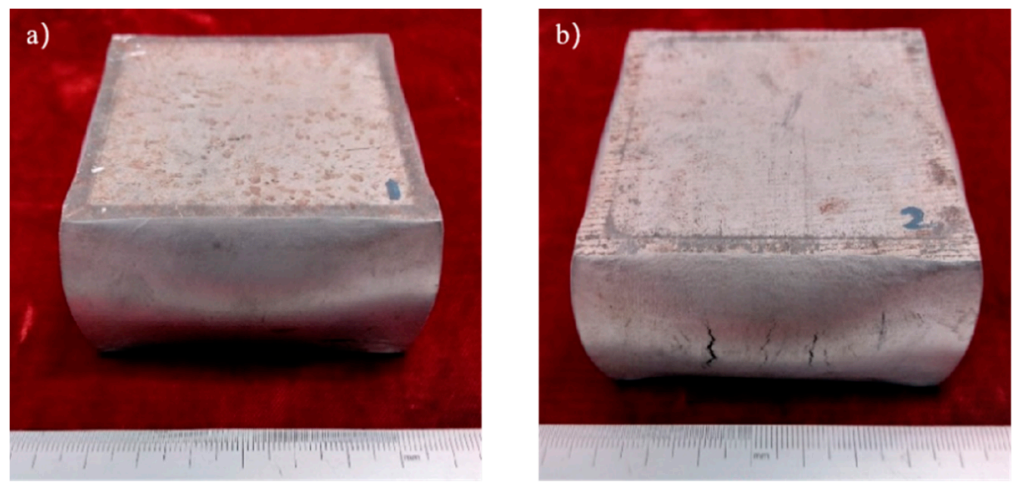

Figure 3. The samples morphology of the aluminum matrix composite: (a) Compression deformation amount of $32.43 \%$; (b) Compression deformation amount of $34.28 \%$.

Table 2. The secondary upsetting morphology of original squeeze casting composites.

\begin{tabular}{|c|c|c|c|}
\hline No. & Morphology of the Samples & Forging Process & Surface Crack \\
\hline 1 & & $\begin{array}{l}\text { 1. Axial compression } 26.83 \% \\
\text { 2. Sample height after deformation } 43.90 \mathrm{~mm}\end{array}$ & $\begin{array}{c}\text { No macroscopic cracks on the } \\
\text { surface }\end{array}$ \\
\hline 2 & & $\begin{array}{l}\text { 1. Axial compression of } 26.83 \% \\
\text { 2. } 480{ }^{\circ} \mathrm{C} \text { for } 1 \mathrm{~h} \\
\text { 3. Axial compression } 14.84 \% \\
\text { 4. Total axial deformation } 41.67 \% \\
\text { 5. Sample height after deformation } 43.90 \mathrm{~mm}\end{array}$ & $\begin{array}{c}\text { Severe macroscopic cracks on } \\
\text { the surface }\end{array}$ \\
\hline 3 & & $\begin{array}{l}\text { 1. Axial compression } 26.83 \% \\
\text { 2. } 480{ }^{\circ} \mathrm{C} \text { for } 1 \mathrm{~h} \\
\text { 3. Axial compression } 10.33 \% \\
\text { 4. Total axial deformation } 37.05 \% \\
\text { 5. Sample height after deformation } 37.70 \mathrm{~mm}\end{array}$ & $\begin{array}{l}\text { Shallow macroscopic cracks } \\
\text { on the surface }\end{array}$ \\
\hline 4 & & $\begin{array}{ll}\text { 1. } & \text { Axial compression } 26.83 \% \\
\text { 2. } & 480{ }^{\circ} \mathrm{C} \text { for } 1 \mathrm{~h} \\
\text { 3. } & \text { Axial compression } 5.17 \% \\
\text { 4. } & \text { Total axial deformation } 32 \% \\
\text { 5. } & \text { Sample height after deformation } 40.80 \mathrm{~mm}\end{array}$ & $\begin{array}{c}\text { No macroscopic cracks on the } \\
\text { surface }\end{array}$ \\
\hline
\end{tabular}

It can be observed from the figure that after the secondary upsetting experiments, it was easy to induce macro cracks on the surface of the samples. When the secondary deformation amount was $5.17 \%$, there were no macro cracks on the surface, but the total axial deformation did not exceed the forging limit of $32.43 \%$. In conclusion, the accumulative deformation of the original squeeze casting after two times upsetting experiments does not exceed the forming limit of one time upsetting. 


\subsection{The Secondary Forgeability of the Aluminum Matrix Composites of Extrusion Samples}

3.3.1. The First Forging Limit of the Extrusion Samples

The samples morphology of the aluminum matrix composite after upsetting test is shown in Figure 4. When the axial compression deformation amount was $46 \%$, the surface of the sample had no macroscopic cracks. When the axial compression deformation amount was $50 \%$, there were only shallow cracks on the surface of the samples. The forming limit of the $\mathrm{SiCw}+\mathrm{Al}_{18} \mathrm{~B}_{4} \mathrm{O}_{33} \mathrm{~W} / 2024 \mathrm{Al}$ composite of extrusion is $46 \%$. The aluminum matrix composite of extrusion has better forgeability than the original squeeze casting.
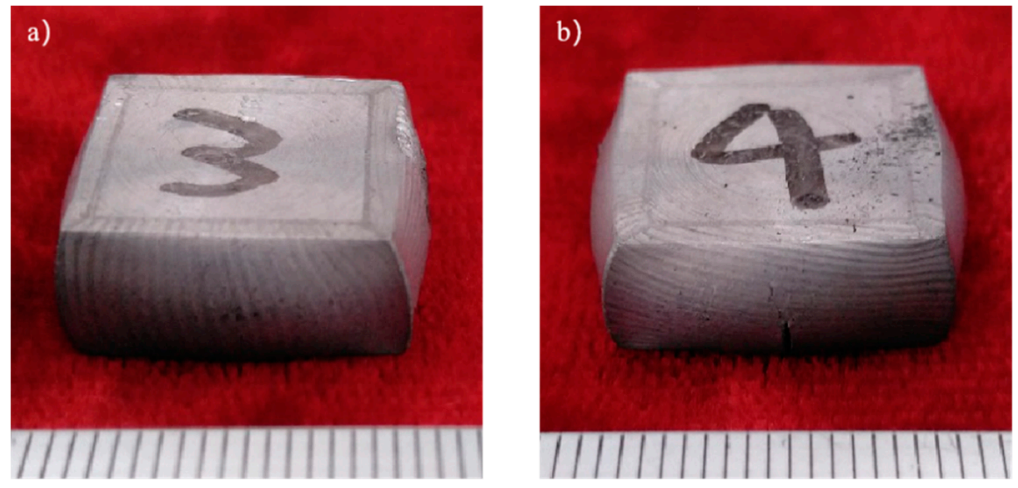

Figure 4. The samples morphology of the aluminum matrix composite: (a) Compression deformation amount of $46 \%$; (b) Compression deformation amount of $50 \%$.

\subsubsection{The Secondary Upsetting Experiment of the Extrusion Samples}

The upsetting experiments of the $\mathrm{SiCW}+\mathrm{Al}_{18} \mathrm{~B}_{4} \mathrm{O}_{33} \mathrm{~W} / 2024 \mathrm{Al}$ composite samples of extrusion were carried out, as shown in Table 3.

Table 3. The secondary upsetting morphology of extruded composites.

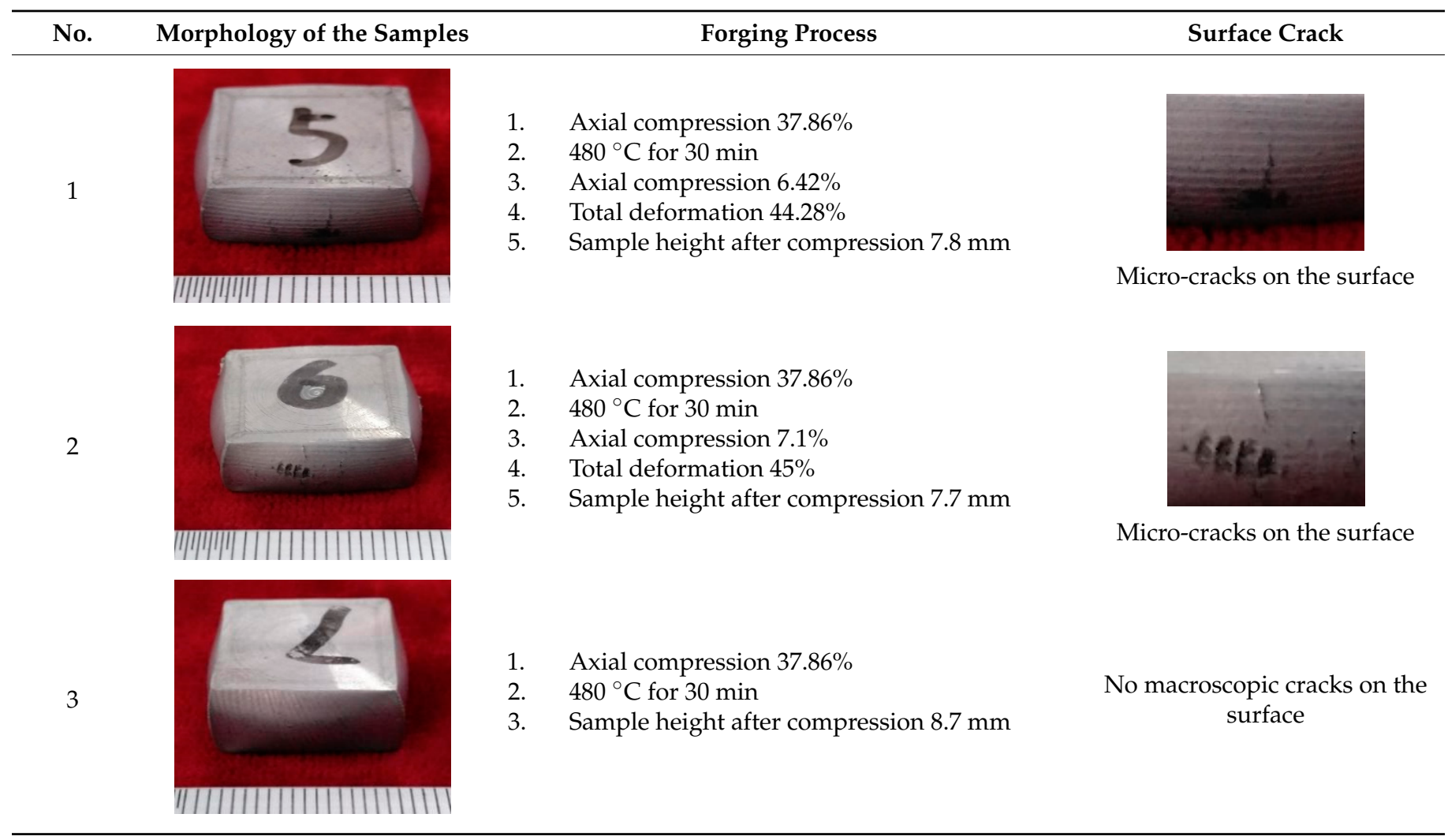


It can be observed from the figure that after the secondary upsetting experiment, micro-cracks appeared on the surface of the samples. The total axial deformation did not exceed the forging limit of $46 \%$. In conclusion, the accumulative deformation of the extrusion after two times upsetting experiments does not exceed the forming limit of one time upsetting.

\section{Discussion}

\subsection{Microstructure of the Original Squeeze Casting Samples}

The SEM photographs of the $\mathrm{SiCw}+\mathrm{Al}_{18} \mathrm{~B}_{4} \mathrm{O}_{33} \mathrm{~W} / 2024 \mathrm{Al}$ matrix composite of the original squeeze casting are shown in Figure 5. The whisker reinforcements are randomly oriented and dispersively distributed in the aluminum matrix, but there are also some partial whisker aggregations, as shown in the red square of Figure $5 \mathrm{~b}$. This is because that the molten aluminum alloy cannot fully penetrate into the gap between the whisker reinforcements during the preparation process of squeeze casting, which results in many defects in the casting composite. These defects are easy to induce stress concentration and micro-cracks during deformation, which reduces the deformation ability of the composite. The second phases with different sizes are dispersively distributed in the aluminum matrix. The result of energy spectrum analysis shows that the main components were $\mathrm{Al}, \mathrm{Si}, \mathrm{Mn}$, etc., the chemical formula of the second phase infers as $\mathrm{Al}_{5} \mathrm{Si}_{2} \mathrm{Mn}$. The casting defects, unevenly distributed whiskers and brittle second phases result poor forgeability of the aluminum matrix composites.
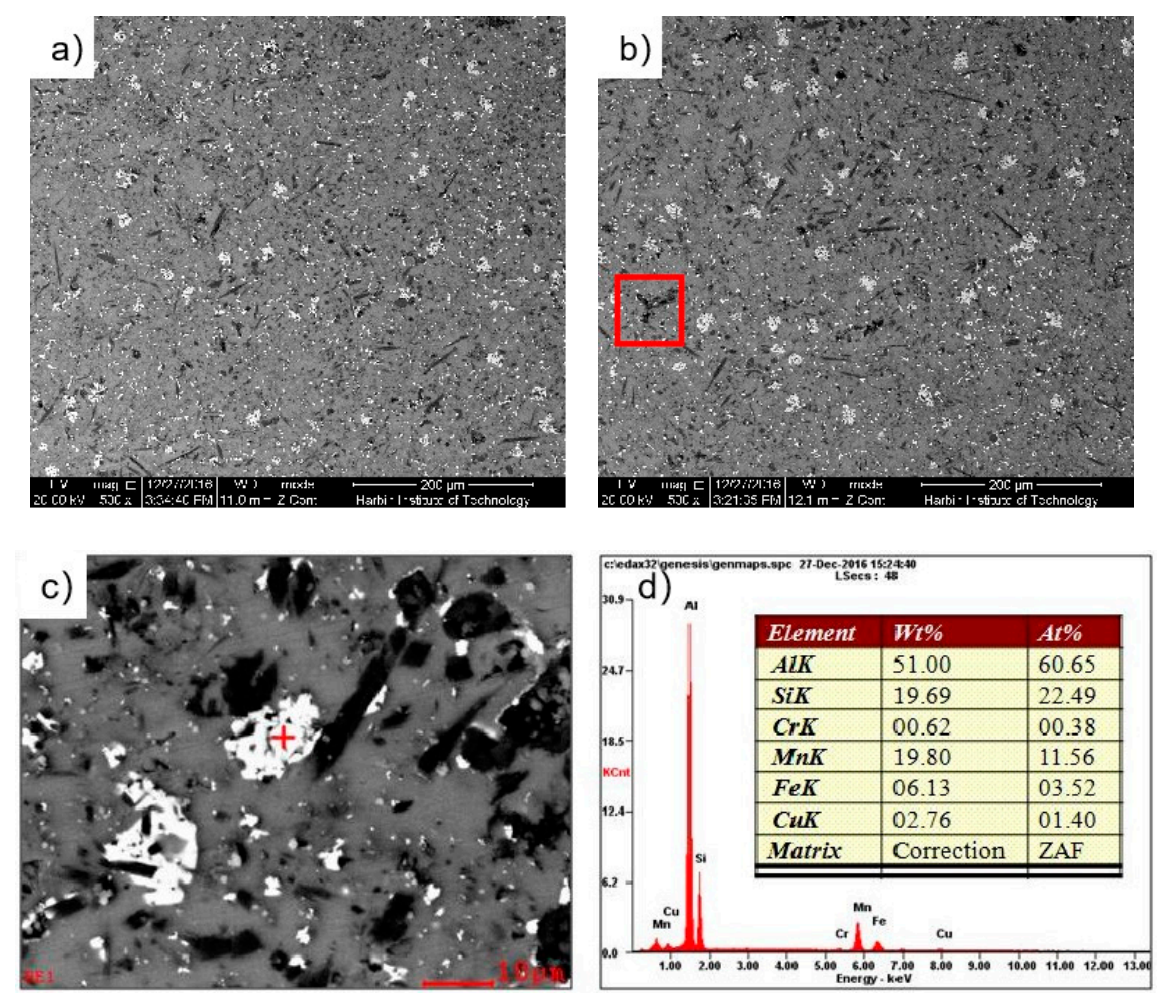

Figure 5. The SEM photograph and second phase energy spectrum of the microstructrue of the casting composite: (a) The horizontal microstructrue of SEM; (b) The vertical microstructrue of SEM; (c) The large second phase in matrix; (d) The energy spectrum of large second phase.

\subsection{Microstructure of the Extrusion Samples}

The SEM photographs of the $\mathrm{SiCw}+\mathrm{Al}_{18} \mathrm{~B}_{4} \mathrm{O}_{33} \mathrm{~W} / 2024 \mathrm{Al}$ matrix composite of sheathed extrusion are shown in Figure 6. Compared with the random distribution of the whiskers of original squeeze casting, most whiskers are parallel to the extrusion direction, and only a few whiskers are perpendicular to the extrusion direction. This is because the whiskers 
rotate during extrusion, the orientation of the whiskers is parallel to the extrusion direction and the whiskers are uniformly distributed in the aluminum matrix. When the extruded composite is axially forced, the reinforced whiskers distributed along the axial direction can most effectively withstand the load transmitted from the matrix. For the original squeeze casting composites, since the wetting angle of $\mathrm{SiC}$ on $\mathrm{Al}$ can be as high as $155^{\circ}$, the molten aluminum alloy with high surface tension is difficult to fill the area of whiskers aggregation. The large number of pores in the matrix alloy not only reduce the density of the aluminum matrix composite, but also easily induce stress concentration during thermoplastic deformation. As there is no matrix support in the whisker aggregation area, the whiskers are likely to fracture during plastic deformation, and micro cracks are induced inside the composite material, these micro-cracks are easily to propagate and form macro cracks. The matrix alloy is under three-dimensional compressive stress during the extrusion process, which can effectively prevent the generation of crack sources and the propagation of cracks and eliminate the squeeze casting defects such as pores and pinholes in the matrix alloy. The porosity decreases, the density increases and the reinforcements are uniformly distributed after extrusion, which make the strength of the matrix alloy increase and achieve better a microstructure and better properties, and, furthermore, create favorable conditions for the secondary forming. The coarse grains of squeeze casting can be refined during extrusion, but there are still some large-size pores that are not eliminated as shown in Figure 6a, the bulk second phases in the whiskers aggregation area are easily to break into micro cracks, which can induce cracking.
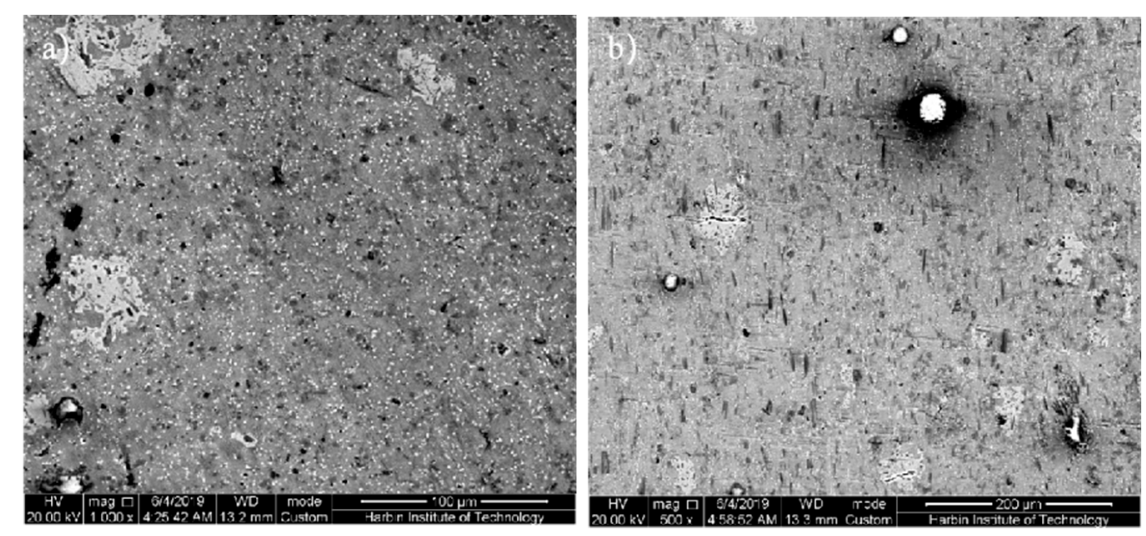

Figure 6. The SEM photograph of the microstructure of the extruded composite: (a) Transverse section; (b) Axial section.

\subsection{Fracture Mechanism of the Aluminum Matrix Composite of the Original Squeeze Casting and Extrusion}

The SiC whisker with excellent chemical stability has no interface chemical reaction with the aluminum matrix, the interface bonding between the aluminum alloy and the whiskers is mainly mechanically physics bonding. Whisker debonding from the matrix is mainly due to the low interface bonding strength. The load is transferred from the matrix to the interface. If the interface bonding strength is higher than the whisker and matrix strength, whisker fracture or matrix interface cracking occurs preferentially. If the interface bonding strength is lower than the whisker and matrix strength, the whiskers detach from the bonding interface and are pulled out from matrix.

The high-temperature tensile fracture at $450{ }^{\circ} \mathrm{C}$ of the aluminum matrix composite of original squeeze casting is shown in Figure 7. The analysis of the tensile fracture surfaces reveal that whiskers fracture mostly occurs on the fracture surface, the whiskers are rarely pulled out from the matrix alloys and there are no obvious separation between the whiskers and the matrix alloys. The orientation of the whisker fracture is often different from the tensile direction, the whiskers tend to rotate or break in the tensile direction. Due to the disordered orientation of the whiskers of the original squeeze casting, there 
are many whiskers perpendicular to the tensile direction and the whiskers break easily during tension, which is the main reason of cracking of aluminum matrix composites. The high-temperature tension fracture of the aluminum matrix composites of original squeeze casting is induced by whisker fracture.

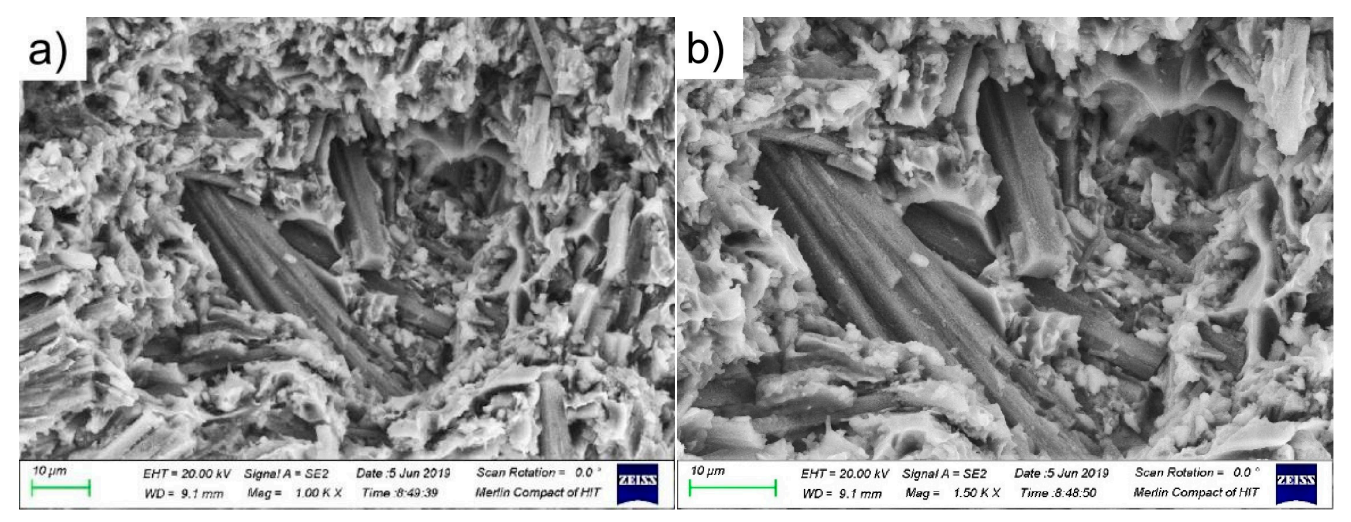

Figure 7. The high-temperature tensile fracture at $450{ }^{\circ} \mathrm{C}$ of the original squeeze casting: (a) 1000 times; (b) 1500 times.

The high-temperature tensile fracture at $450{ }^{\circ} \mathrm{C}$ of the aluminum matrix composite of extrusion is shown in Figure 8. A large number of pits can be observed, which were left by the whiskers pulled out from the matrix. The defects of the squeeze casting such as pores are reduced after sheathed extrusion, and the whiskers are oriented along the extrusion direction. The whiskers in the original squeeze casting are randomly distributed, rotate in the direction of tension during the tensile deformation and are easy to crack in this process. However, the randomly distributed whiskers will bear the shear force in the tensile direction, which increases the strength of aluminum matrix composites. Therefore, the tensile strength is affected by two aspects of whisker orientation. Different from the original squeeze casting, the orientation of the whiskers in the extrusion are uniformly distributed in the direction of extrusion, the orientation of the whiskers is consistent with the tensile direction during the tensile deformation, the whiskers rarely rotate, and the load is transferred from the matrix to the interface. Due to the low bonding strength of the whiskers and the matrix interface, most of the whiskers are pulled out from the interface. The high-temperature tensile strength and elongation of the extruded aluminum matrix composite are mostly affected by the interface strength, the interface between the matrix and whiskers is smooth and there is no chemical reaction at the interface. The bonding between the matrix and the whisker at the interface is mainly mechanically physics bonding, so the interface combining ability is weak.
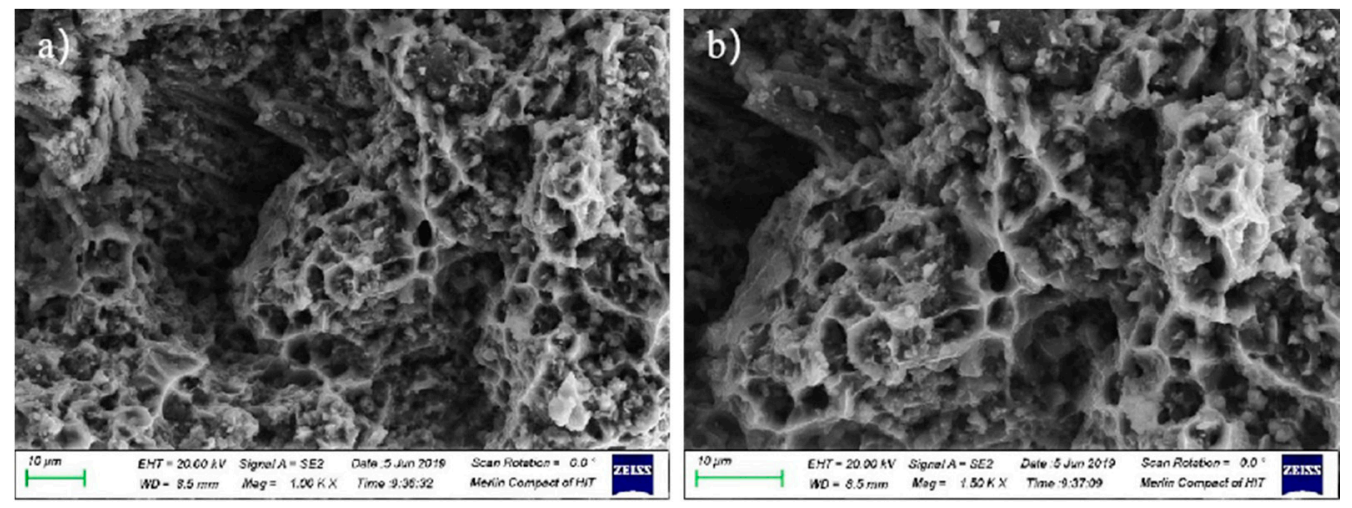

Figure 8. The high-temperature tensile fracture at $450{ }^{\circ} \mathrm{C}$ of the extrusion: (a) 1000 times; (b) 1500 times. 
The $\mathrm{SiCw}+\mathrm{Al}_{18} \mathrm{~B}_{4} \mathrm{O}_{33} \mathrm{w} / 2024 \mathrm{Al}$ composites are whisker-reinforced composites. According to the shear lag model in mechanics of short fiber composites, the critical aspect ratio of whiskers in the whisker-reinforced aluminum matrix composite is shown in Equation (1).

$$
\frac{L c}{d}=\frac{\sigma_{f f}}{4 \tau_{b}}
$$

In this equation:

$\sigma_{f f}$ is the breaking strength of the whiskers,

$\tau_{b}$ is the shear strength of the interface,

$L_{c}$ is the length of the whiskers,

$d$ is the diameter of the whiskers.

When the aspect ratio of the whiskers of the aluminum matrix composites is higher than the critical aspect ratio, the whiskers can withstand the load from the matrix, the pullout of the whiskers is the main form of fracture at this time. The aspect ratio of the $\mathrm{SiCW}+\mathrm{Al}_{18} \mathrm{~B}_{4} \mathrm{O}_{33} \mathrm{w} / 2024 \mathrm{Al}$ composites prepared by squeeze casting is constant, and the breaking strength of the whiskers is determined by the whisker materials. The whisker breaking strength is a constant value. From the definition equation of critical aspect ratio, it can be found that the critical aspect ratio of whiskers of $\mathrm{SiCW}+\mathrm{Al}_{18} \mathrm{~B}_{4} \mathrm{O}_{33} \mathrm{~W} / 2024 \mathrm{Al}$ composites is inversely proportional to the shear strength of the matrix interface, the higher the strength of the matrix, the lower the critical aspect ratio of the whiskers of the aluminum matrix composite. After sheathed extruding the $\mathrm{SiCw}+\mathrm{Al}_{18} \mathrm{~B}_{4} \mathrm{O}_{33} \mathrm{~W} / 2024 \mathrm{Al}$ composite of the original squeeze casting, the whiskers rotate because of the partial nonuniform plastic flow, the whiskers fracture under severe three-dimensional compressive stress. Therefore, the aspect ratio of the whisker of the extruded aluminum matrix composite is smaller than that of the original squeeze casting. Compared with the extrusion, there are a larger number of whiskers exceeding the critical aspect ratio in the original squeeze casting, which results in more whiskers of the original squeeze casting being loaded. Thus, in the tensile fracture of the aluminum matrix composites of original squeeze casting, the fracture of the whiskers exceeding critical aspect ratio is the main fracture form, while in the tensile fracture of the extruded aluminum matrix composite, the pullout of the whiskers below the critical aspect ratio is the main fracture form.

\subsection{Microstructure of the Original Squeeze Casting Samples after Secondary Upsetting}

Compared with the original squeeze casting, the orientation of the whiskers inside the material changes significantly after upsetting to the forming limit of the aluminum matrix composite.

After the first upsetting deformation, the whiskers rotate and break, as shown in Figure 9. The work hardening occurs inside the matrix due to plastic deformation and a large amount of dislocation accumulates at the interface. As shown in Figure 10a,b,a large amount of dislocations are accumulated at the grain boundary and the needle-shaped second phase. The samples were heat preserved at $480{ }^{\circ} \mathrm{C}$, the holding time is consistent to that of the first upsetting and the dislocation density decreases after recovery of the matrix. The dislocation density at the second phase is significantly reduced, as shown in Figure 10c, and the work hardening effect of the matrix is reduced. However, the whiskers continue rotate during the second upsetting deformation, the nonuniform flow of metal in the matrix causes the whiskers to withstand bending torque and dislocations are accumulated at the interface, which makes the whiskers continue to break during rotation. The $\mathrm{Al}_{18} \mathrm{~B}_{4} \mathrm{O}_{33} \mathrm{~W}$ is accumulated at the interface as shown in Figure $10 \mathrm{~d}$. In the process of rotating and breaking of the whiskers, the dislocation density of the matrix decreases after recovery, and the flow ability of the matrix decreases due to work hardening, and the dislocations at the whisker interface are reduced, which is conducive to increase the secondary deformation amount. Due to the recovery softening of matrix metal, the deformation resistance is reduced, the flow ability of the matrix is relatively improved and the difference of the partial deformation rates are also increased. In addition, due to 
the decrease of the deformation resistance of the matrix, the proportion of the loading on whiskers increases, which makes the whiskers easier to rotate and break. The softening of matrix metal affects the secondary forgeability in two aspects. For the aluminum matrix composite, the whisker fracture has a greater effect on reducing plasticity, so it does not exhibit secondary forgeability similar to traditional metal.
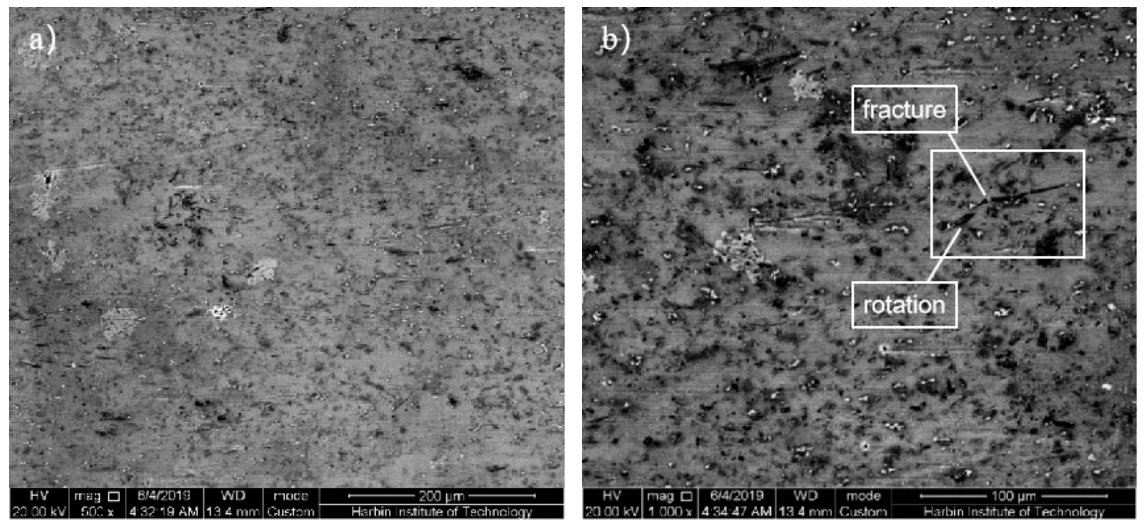

Figure 9. The SEM microstructure of samples after the first upsetting deformation: (a) 500 times; (b) 1000 times.
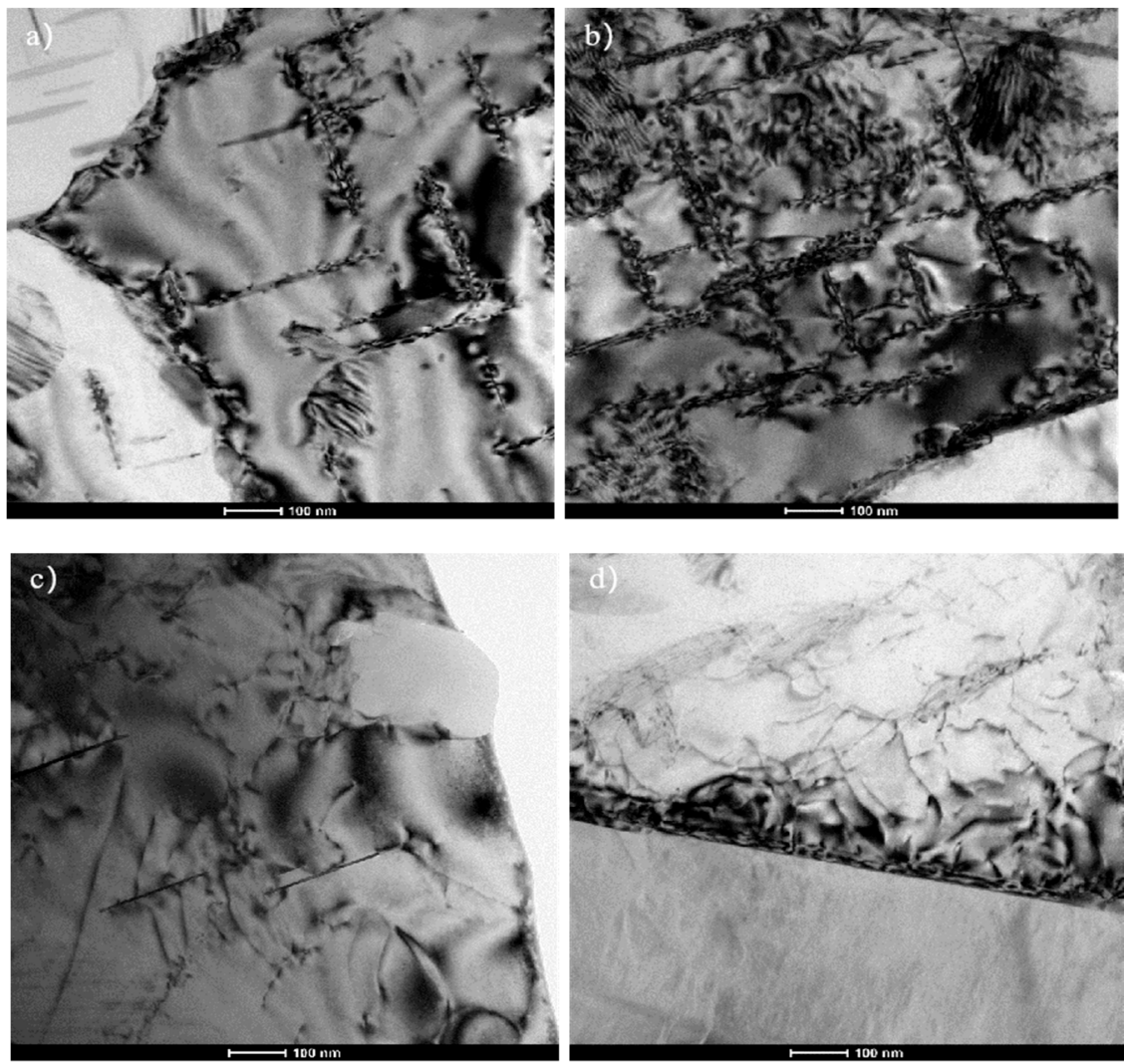

Figure 10. Accumulation of the dislocations at the interface: (a) Accumulation of the dislocations at grain boundaries; (b) Accumulation of the dislocations at the interface of the second phase; (c) Accumulation of the dislocations at the second phase after heat preserving; (d) Accumulation of the second deformation dislocations at the $\mathrm{Al}_{18} \mathrm{~B}_{4} \mathrm{O}_{33} \mathrm{~W}$ interface.

\subsection{Microstructure of the Extrusion Samples after Secondary Upsetting}

The transmission bright field image of the extruded aluminum matrix composite is shown in Figure 11. There are a large number of dislocations at the whisker interface, 
which form dislocation walls. According to the map scanning analysis of each element, the distribution of whiskers and matrix can be visually observed. The distribution of the coincidence of $\mathrm{Si}$ and $\mathrm{C}$ elements can reflect the distribution of $\mathrm{SiC}$ whiskers. The distribution of $\mathrm{Cu}$ and $\mathrm{Al}$ indicates that $\mathrm{Cu}$ segregates in the form of $\mathrm{CuAl}_{2}$ on the surface of $\mathrm{SiC}$ whiskers, $\mathrm{O}$ is enriched at the interface of the outer layer of $\mathrm{CuAl}_{2}$ and formed an $\mathrm{Al}_{2} \mathrm{O}_{3}$ layer with a thickness of $200 \mathrm{~nm}$ to $400 \mathrm{~nm}$. The SiC whisker interface is flat, there is no chemical reaction with the matrix and no interface reactants are observed at the interface.

Compared to the random orientation and dispersive distribution of the whiskers of the original squeeze casting, the orientation and distribution of whiskers have changed greatly, the decrease in the aspect ratio of the whiskers and the distribution of the whiskers change the fracture mechanism of high-temperature tensile after extrusion and whisker pullout is the main form of fracture. This means that the extruded aluminum matrix composite has better whisker orientation and distribution which protects the whiskers from breaking during tensile deformation. Although the orientation of the whiskers of the extruded aluminum matrix composite is parallel to the extrusion direction, which is beneficial to the tensile deformation, the secondary upsetting is different from the tensile deformation. After the first upsetting deformation and heat preservation, the matrix generates sub-grain boundaries during recovery, as shown in Figure 12a. Dislocations in the matrix are greatly reduced, and the matrix is softened, but the whiskers have already rotated after the first upsetting and the angle between the whiskers and extrusion direction is $29^{\circ}$. The whiskers still rotate and break during the secondary upsetting, as shown in Figure 12c,d.
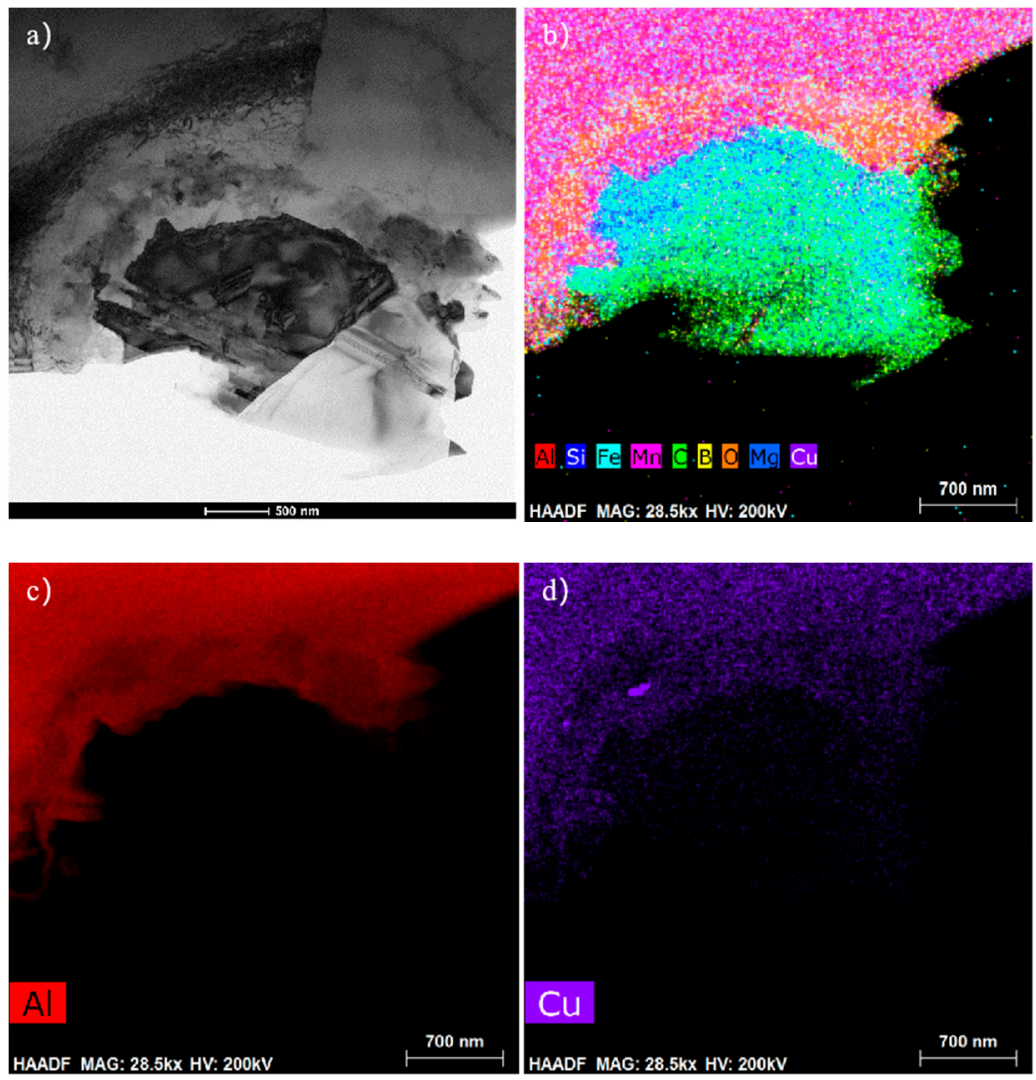

Figure 11. Cont. 

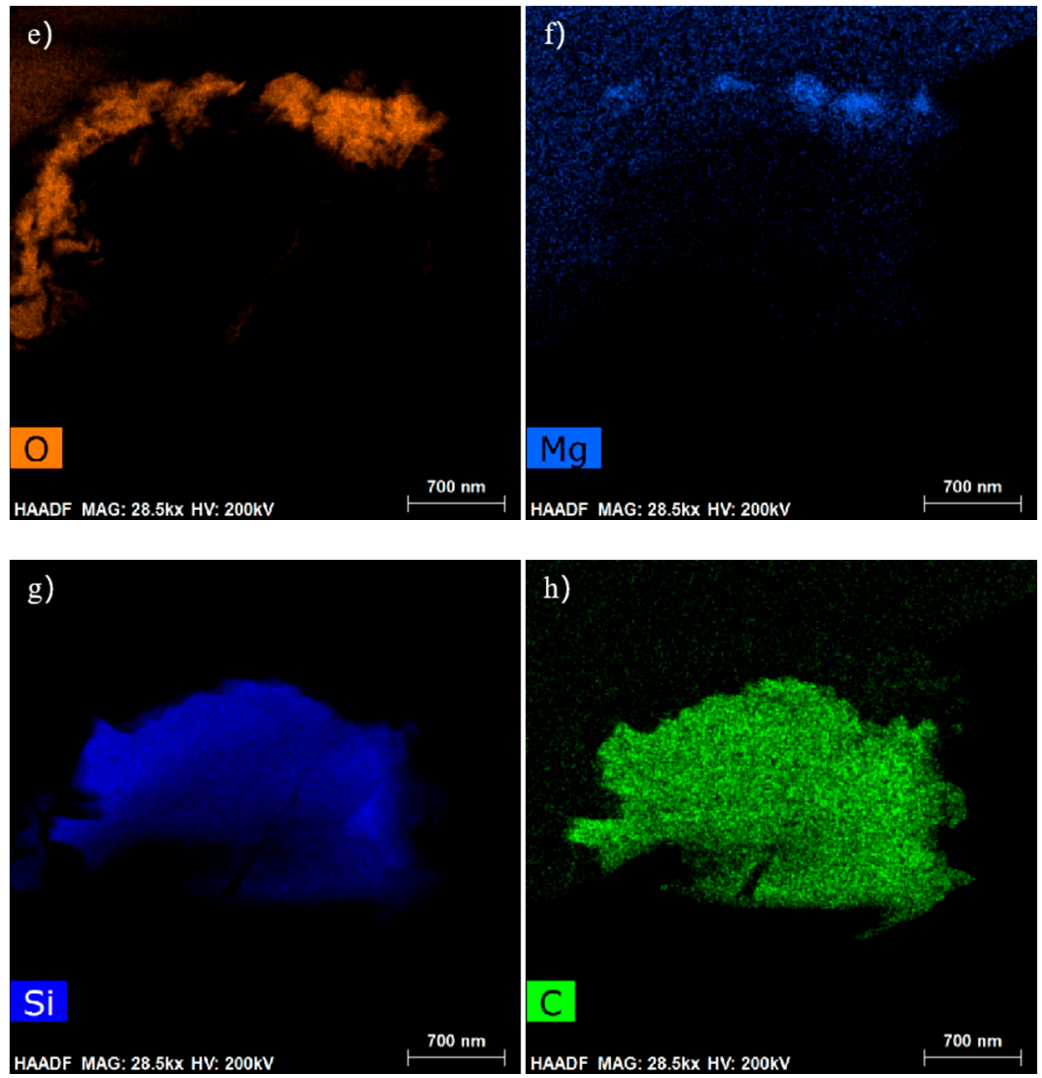

Figure 11. The transmission map scanning after compression: (a) The bright-field image; (b) The distribution of all elements, The element distribution of (c) $\mathrm{Al}$; (d) $\mathrm{Cu}$; (e) $\mathrm{O}$; (f) $\mathrm{Mg}$; (g) $\mathrm{Si}$; (h) C.
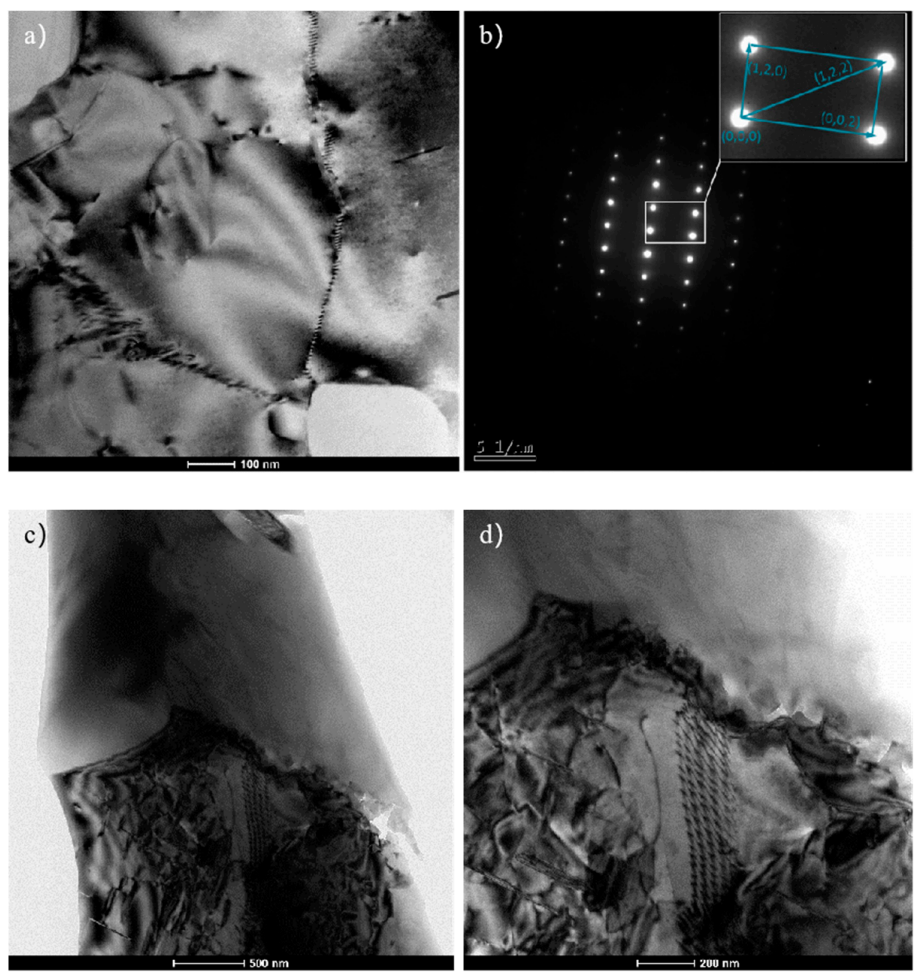

Figure 12. Recovery and whisker fracture of the extruded aluminum matrix composites: (a) The sub-grain boundary; (b) $\mathrm{Al}_{18} \mathrm{~B}_{4} \mathrm{O}_{33} \mathrm{w}$ diffraction spots; (c) The whisker fracture; (d) The interface at the fracture of the whisker. 
For the aluminum matrix composite of original squeeze casting, the internal whiskers are randomly distributed. During tension, the whiskers with disorderly orientation and distribution rotate in tensile direction due to tensile stress. The whiskers in the vertical tensile direction withstand shear stress, which commonly makes the whiskers break during tensile, as shown in Figure 13a. The disorderly whiskers are easily broken by partial nonuniform flow stress during upsetting, as shown in Figure 13b, which limits the aluminum matrix composites to exhibit secondary forgeability.

a)
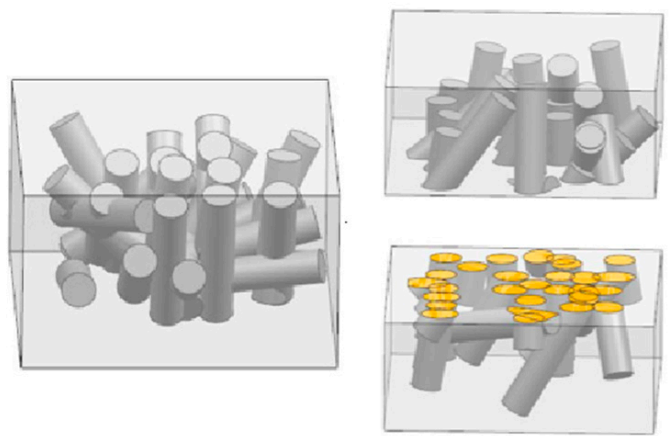

b)
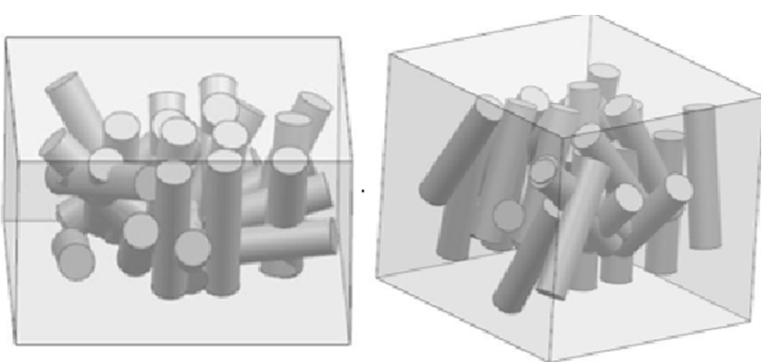

Figure 13. The schematic diagrams of the deformation of the original squeeze casting: (a) Aluminum matrix composites during tension; (b) Aluminum matrix composites during upsetting.

The aspect ratio of the whiskers of aluminum matrix composite was measured by SEM Photographs with high magnification, as shown in Figure 14. It can be seen that the aspect ratio decreases after extrusion due to the fracture of part of the whiskers. As a result of the specific orientation and the decrease of the aspect ratio of the whiskers, a large number of whiskers are under uniform stress field during tension and only a small part of the whiskers rotate or break, which results in better plastic deformation ability and higher elongation of the aluminum matrix composite, as shown in Figure 15. Although the extruded aluminum matrix composites show higher elongation in tensile test, the direction of the whiskers parallel to the extrusion direction changes due to the deformation of the matrix during the first upsetting deformation, leading to some whiskers rotating and breaking in the upsetting deformation. The cracks in the aluminum matrix composites reinforced with high volume fraction whiskers are easily propagated, thus the extruded aluminum matrix composites do not have the secondary forgeability due to whisker rotation fracture. 

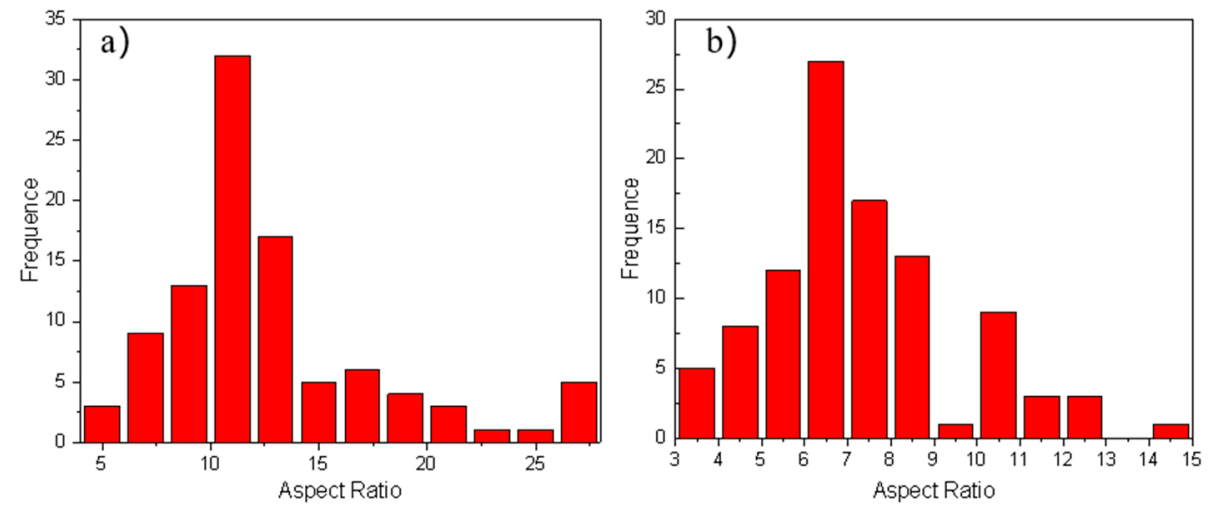

Figure 14. The change of the aspect ratio after extrusion: (a) The original squeeze casting, (b) The extrusion.

a)
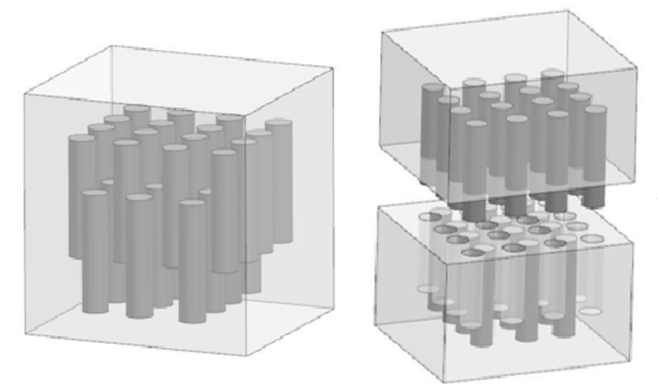

b)
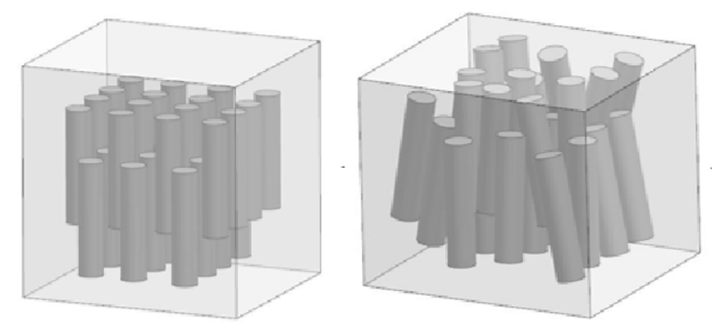

Figure 15. The schematic diagrams of the deformation of the extrusion: (a) Aluminum matrix composites during tension; (b) Aluminum matrix composites during upsetting.

\section{Conclusions}

In the study of the secondary forgeability of the $20 \mathrm{vol} \% \mathrm{SiCw}+\mathrm{Al}_{18} \mathrm{~B}_{4} \mathrm{O}_{33} \mathrm{~W} / 2024 \mathrm{Al}$ whisker reinforced composite using the original squeeze casting and extruded samples, the results can be outlined as follows:

(1) The surface forming quality of the extruded bars is different at different positions, and the extruded bars are easy to induce macro cracks. Bars with better forming surface quality can be obtained by using sheathed extrusion, and the extrusion forming quality of aluminum matrix composite can be improved. Although there are few transverse cracks on the sheath, the surface of $\mathrm{SiCw}+\mathrm{Al}_{18} \mathrm{~B}_{4} \mathrm{O}_{33} \mathrm{w} / 2024 \mathrm{Al}$ matrix composite has no macro cracks after removing the sheath, indicating that the forming quality of the composite is excellent. The porosity decreases, the density increases and the reinforcements are uniformly distributed after extrusion, which make the strength of the matrix alloy increase and achieve better microstructure and properties.

(2) The upsetting test of aluminum matrix composites of the original squeeze casting and extrusion was carried out to determine the forming limit. The forming limit of the original squeeze casting composite is $32.43 \%$, and that of extruded composite is $46 \%$. The accumulative deformation after two times upsetting experiments does not exceed the forming limit of one time upsetting. The results show that $20 \mathrm{vol} \% \mathrm{SiCw}+\mathrm{Al}_{18} \mathrm{~B}_{4} \mathrm{O}_{33} \mathrm{w} / 2024 \mathrm{Al}$ 
whisker reinforced composites of the original squeeze casting and extrusion do not has the secondary forgeability. This is not similar to traditional metals.

(3) The $\mathrm{SiCw}+\mathrm{Al}_{18} \mathrm{~B}_{4} \mathrm{O}_{33} \mathrm{w} / 2024 \mathrm{Al}$ whisker reinforced composites of the original squeeze casting and extrusion do not has the secondary forgeability. Although the aluminum matrix still has recovery ability, and the matrix dislocation density decreases during the heat preservation, the whiskers are easy to rotate and fracture, and the pores and cracks formed by whisker fracture continue to expand during the secondary deformation, which leads to further propagation of macroscopic cracks. This means that it is difficult to form complex forgings of high volume fraction whisker reinforced aluminum matrix composite of the original squeeze casting by traditional forging methods, even though strict isothermal forging methods.

Author Contributions: Conceptualization, Z.Z., L.Y. and D.S.; Formal analysis, L.W.; Investigation, L.W. and J.L.; Methodology, B.G., L.Y. and F.X.; Validation, J.L.; Visualization, S.X.; Writing-original draft, S.X.; Writing-review \& editing, Z.Z. and B.G. All authors have read and agreed to the published version of the manuscript.

Funding: This research was funded by [the National Key R\&D Program of China] grant number [2018YFB1309100] and the APC was funded by [2018YFB1309100].

Institutional Review Board Statement: Not applicable.

Informed Consent Statement: Not applicable.

Data Availability Statement: Data sharing not applicable.

Acknowledgments: This project is sponsored by the National Key R\&D Program of China (2018YFB1309100).

Conflicts of Interest: The authors declare no conflict of interest.

\section{References}

1. Sharma, P.; Khanduja, D.; Sharma, S. Tribological and mechanical behavior of particulate aluminum matrix composites. J. Reinf. Plast. Compos. 2014, 33, 2192-2202. [CrossRef]

2. Jin, P.; Liu, Y.; Li, S. Aerospace Applications of Particulate Reinforced Aluminum Matrix Composites. Mater. Rep. 2009, 23, 24-27.

3. Reddy, M.P.; Manakari, V.; Parande, G.; Shakoor, R.; Mohamed, A.; Gupta, M. Structural, mechanical and thermal characteristics of Al-Cu-Li particle reinforced Al-matrix composites synthesized by microwave sintering and hot extrusion. Compos. Part B-Eng. 2019, 164, 485-492. [CrossRef]

4. Zhang, C.; Zeng, Y.P.; Yao, D.; Yin, J.; Zuo, K.; Xia, Y.; Liang, H. The improved mechanical properties of Al matrix composites reinforced with oriented beta-Si3N4 whisker. J. Mater. Sci. Technol. 2019, 35, 1345-1353. [CrossRef]

5. Seleman, M.M.E.; Ahmed, M.M.Z.; Ataya, S. Microstructure and mechanical properties of hot extruded 6016 aluminum alloy/graphite composites. J. Mater. Sci. Technol. 2018, 34, 1580-1591. [CrossRef]

6. Wang, Z.G.; Li, C.P.; Wang, H.Y. Aging Behavior of Nano-SiC/2014Al Composite Fabricated by Powder Metallurgy and Hot Extrusion Techniques. J. Mater. Sci. Technol. 2016, 32, 1008-1012. [CrossRef]

7. Ma, K.; Liu, Z.Y.; Bi, S.; Zhang, X.X.; Xiao, B.L.; Ma, Z.Y. Microstructure evolution and hot deformation behavior of carbon nanotube reinforced 2009Al composite with bimodal grain structure. J. Mater. Sci. Technol. 2021, 70, 73-82. [CrossRef]

8. Asadikiya, M.; Yang, S.; Zhang, Y.; Lemay, C.; Apelian, D.; Zhong, Y. A review of the design of high-entropy aluminum alloys: A pathway for novel Al alloys. J. Mater. Sci. 2021, 56, 12093-12110. [CrossRef]

9. Chak, V.; Chattopadhyay, H.; Dora, T.L. A review on fabrication methods, reinforcements and mechanical properties of aluminum matrix composites. J. Manuf. Process. 2002, 56, 1059-1074. [CrossRef]

10. Yi, L.F.; Yoshida, N.; Yamamoto, T.; Onda, T.; Chen, Z.C. Microstructure and thermal/mechanical properties of hot-extruded aluminum/graphite composites with Al-Si alloy addition. J. Mater. Sci. 2019, 54, 9933-9944. [CrossRef]

11. Sha, J.J.; LÜ, Z.Z.; Sha, R.Y.; Zu, Y.F.; Dai, J.X.; Xian, Y.Q.; Zhang, W.; Ding, C.U.; Yan, C.L. Improved wettability and mechanical properties of metal coated carbon fiber-reinforced aluminum matrix composites by squeeze melt infiltration technique. Trans. Nonferrous Met. Soc. China 2021, 31, 317-330. [CrossRef]

12. Pandey, N.; Chakrabarty, I.; Barkane, K.; Mehta, N.S.; Majhi, M.R. Microstructure, mechanical and wear properties of aluminum borate whisker reinforced aluminum matrix composites. Trans. Nonferrous Met. Soc. China 2020, 30, 1731-1742. [CrossRef]

13. Samal, P.; Vundavilli, P.R.; Meher, A.; Mahapatra, M.M. Recent progress pin aluminum metal matrix composites: A review on processing, mechanical and wear properties. J. Manuf. Process. 2020, 59, 131-152. [CrossRef]

14. Lau, K.T.; Hui, D. The revolutionary creation of new advanced material-carbon nanotube composites. Compos. Part B Eng. 2002, 33, 263-277. [CrossRef] 
15. Jiang, J.F.; Wang, Y.; Liu, Y.Z.; Xiao, G.F.; Li, H. Microstructure and mechanical properties of 7005 aluminum alloy processed by one-pass equal channel reciprocating extrusion. Trans. Nonferrous Met. Soc. China 2020, 31, 609-625. [CrossRef]

16. Tzamtzis, S.; Barekar, N.S.; Babu, N.H.; Patel, J.; Dhindaw, B.K.; Fan, Z. Processing of advanced Al/SiC particulate metal matrix composites under intensive shearing-A novel Rheo-process. Compos. Part A Appl. Sci. Manuf. 2009, 40, 144-151. [CrossRef]

17. Zeng, X.H.; Xu, R.; Tan, Z.Q. Progress of Advanced Aluminum Matrix Composites Research. Mater. China 2015, 34, 417-424.

18. Ji, Y.M.; Yuan, Y.P.; Zhang, W.Z. Elevated Temperature Tensile Creep Behavior of Aluminum Borate Whisker-Reinforced Aluminum Alloy Composites (ABOw/Al-12Si). Materials 2021, 14, 1217. [CrossRef]

19. Sitek, R.; Szustecki, M.; Zrodowski, L.; Wysocki, B.; Jaroszewicz, J.; Wisniewski, P.; Mizera, J. Analysis of Microstructure and Properties of a Ti-AlN Composite Produced by Selective Laser Melting. Materials 2020, 13, 2218. [CrossRef]

20. Fu, X.L.; Li, Y.; Schuh, C.A. Temperature, strain rate and reinforcement volume fraction dependence of plastic deformation in metallic glass matrix composites. Acta Mater. 2007, 55, 3059-3071. [CrossRef]

21. Wei, S.H.; Nie, J.H.; Liu, Y.Q. Effect of Isothermal Forging on Fracture Toughness of Aluminum Matrix Composites Reinforced by Silicon Carbide Particles. Rare Met. Mat. Eng. 2017, 46, 3464-3468.

22. Wu, Q.; Xu, W.X.; Zhang, L.C. Microstructure-based modelling of fracture of particulate rein-forced metal matrix composite. Compos. Part B-Eng. 2019, 163, 384-392. [CrossRef]

23. Narayan, S.; Rajeshkannan, A. Studies on formability of sintered aluminum composites during hot deformation using strain hardening parameters. J. Mater. Res. Technol. 2017, 6, 101-107. [CrossRef]

24. Fu, M.S.; Xiao, Y.H.; Peng, C.G. Influence of the Two-fold Hot Pressing Deformation Technology on the Uniformity of the Microstructure of Powder Metallurgycal SiCp/Al Composite Material. Hot Work. Technol. 2000, 6, 27-29.

25. Hu, Y.B.; Wang, J.F.; Pan, F.S. Research on Fracture and Strengthening Mechanisms of SiCp/6066 Aluminum Matrix Composites with Canned Hot Extrusion. Mater. Rep. 2007, 21, 151-153.

26. Qu, S.J.; Geng, L.; Cao, G.J. Microstructure and Properties of Deformable SiCp/Al Composite Fabricated by Squeeze Casting Method. Acta Mater. Compos. Sin. 2003, 20, 69-73.

27. Zhang, X.N.; Geng, L.; Wang, G.S. Effect of Hot Extrusion on the Microstructure and Mechanical Properties of (SiCw·SiCp)/2024Al hybrid nanocomposites. Mater. Rep. 2004, 12, 482-485.

28. Xu, W.; Jin, X.; Xiong, W.; Zeng, X.; Shan, D. Study on hot deformation behavior and workability of squeeze-cast 20vol\% $\mathrm{SiCw} / 6061 \mathrm{Al}$ composites using processing map. Mater. Charact. 2018, 135, 154-166. [CrossRef]

29. Yuan, L.; Shi, W.; Shivpuri, R.; Xu, F.; Shan, D. Increased hot forgeability of 2024Al/Al18B4O33 whisker composites at high strain rates. J. Mater. Process. Technol. 2017, 243, 456-464. [CrossRef]

30. Leng, J.; Wu, G.; Zhou, Q.; Dou, Z.; Huang, X. Mechanical properties of SiC/Gr/Al composites fabricated by squeeze casting technology. Scr. Mater 2008, 59, 619-622. [CrossRef] 